\title{
Canvas Model as a Tool for Research Projects: A Theoretical Approach
}

\author{
Félix O. Socorro Márquez $\mathbb{D D}^{1}$ and Giovanni E. Reyes Ortiz $\mathbb{D}^{2}$ \\ ${ }^{1}$ Complutense University of Madrid, School of Economic and Business Sciences, \\ Department of Business Organization and Marketing, Madrid, Spain \\ ${ }^{2}$ Universidad del Rosario, Bogotá, Colombia \\ Correspondence should be addressed to Félix O. Socorro Márquez; felix.socorro@gmail.com
}

Received 9 August 2021; Accepted 18 January 2022; Published 8 February 2022

Academic Editor: Ehsan Rezvani

Copyright (C) 2022 Félix O. Socorro Márquez and Giovanni E. Reyes Ortiz. This is an open access article distributed under the Creative Commons Attribution License, which permits unrestricted use, distribution, and reproduction in any medium, provided the original work is properly cited.

\begin{abstract}
The main aim of this study is to offer an easy and practical research model to guide the research activity of students and thereby reduce the syndrome of $\mathrm{ABD}$ (All but Dissertation) and, at the same time, make it easier for evaluators to visualize the development of research projects to guide students more efficiently. The Canvas model proposed by Osterwalder and Pigneur in 2011 - for the formulation of business plans - has been the source of inspiration for the instrument proposed by the authors of this study. That model has been adjusted and reformulated by the researchers for the development, synthesis, and presentation of the research projects in the academic field, resulting in the proposal of the Canvas Model for Research Projects (CMRP). For developing this instrument, the researchers have mainly used a qualitative methodology, although part of the analysis and proposals reflected in this study come from a brief empirical trial carried out with a small group of students to validate the configuration and utility of the ten elements that make up the proposed model. The result-both the documentary review, which served as the basis for the combination and distribution of the components of the proposed model, and the brief trial carried out by the researchers-allowed us to observe, in a first approach, the usefulness of the instrument in the preparation of research projects and its utility as an evaluation tool of academic research projects.
\end{abstract}

\section{Introduction}

In traditional education, requiring students to submit a final paper is a necessity. With this paper, it is expected that, among other things, the students demonstrate the management of the knowledge acquired during their studies. Furthermore, educational institutions said that the paper can be understood as a contribution to the career the students are undertaking, especially specific fields of research they have previously established. The final research work may be represented by an essay, a monograph, a dissertation, a degree project, a thesis, or any other document where the scientific method can be incorporated, through either qualitative, quantitative research, or the combination of these two.

It is necessary to highlight what is understood by these academic research projects since, through this, its importance in the professional development of both undergraduate and graduate students can be inferred.

According to López [1], the degree project or thesis prepares the student "for the study, research and development of a specific topic, topic or material, thus allowing them to gain experience in this regard" (p. 1).

On the other hand, for the Autonomous University of Occident (UAO) [2], the degree project is

An in-depth exercise that through the integration and theoretical or theoretical-practical application of knowledge and skills or through the generation of new knowledge, seeks to strengthen the different skills acquired during its training process and, likewise, contribute to the analysis and creative solution of a problem related to the object of study or field of action of your profession. (UAO, n.d., p.1) 
As has been mentioned, the statement made by the UAO (n.d.) applies to both undergraduate and postgraduate studies. Therefore, it could be understood that the research project (essay, monograph, dissertation, or thesis) is a final requirement to opt for the degree. This one is usually carried up in the last semesters of the specific carrier.

Nevertheless, students often consider research activities as difficult tasks to endure. Abreu [3] assures that some "university students perceive research projects as a kind of karma, a requirement without any value or, simply, an absurd requirement in the trajectory of university training" (p. 247). And it is precisely there, at the moment that the student faces the need to carry out a final degree project, which is the problem that this article occupies, especially when it comes to the presentation of monographs, degree projects, thesis, or final works by students from the last years, regardless of the guidelines provided by the institution where they are trained.

In general, students present problems to "capture" and "sell" their research topic, using the traditional tools that exist for it, which could lead to the so-called ABT syndrome or "All but Thesis" syndrome, also known as "All but Dissertation" or ABD.

Regarding the aforementioned syndrome, Abreu et al. [3] explain that "the term "All but Thesis" (ABT) is a fundamentally unofficial term that identifies a stage in the process of obtaining an academic degree" (p. 246). That stage is related to those cases in which the student has accomplished all the classes that the professional career requires completing and, at the same time, has fulfilled all the requirements for his/her graduation, except the presentation of a research project or thesis. This situation prevents him/ her from officially obtaining the professional title.

There are studies, such as the one carried out by Ferrer and Malaver [4], that relate the absence of the research project, at the end of an academic career, with the lack of study plans, the lack of effective academic strategies for its realization, the absence of motivation or the inadequate follow-up by teachers or tutors, factors that can lead to the "all but dissertation" (ABD) syndrome.

For his part, Gheller [5] considers that, regarding the aforementioned subject, "the factors that have been most analysed, as reported in the literature consulted so far, are psychological, instructional and institutional factors" (p.17).

The instructional aspect, mentioned by Gheller [5], is of significant importance in terms of addressing the problem set forth here and the model that is sought to be proposed to influence the solution, as well as the "lack of effective academic strategies for its accomplishment" mentioned by Ferrer and Malaver [4].

According to Darling, Hammond, and Snyder (2000), cited by Badia and Gómez [6], the instructional context must be understood as "a complex and dynamic framework of didactic variables that can interact with each other in different ways and that condition the way in which that a teacher develops the pedagogical design of a course" (p. 170).

Therefore, it could be assumed that the way in which the instructional model is developed can influence the performance and understanding of the course. If it is appropriate, it could lead to a successful conclusion, in the case of the problem being addressed; it would lead to the completion of the final research project or, on the contrary, to the materialization of the $\mathrm{ABD}$ syndrome.

According to [6], cited by Badia and Gómez [6], teachers' teaching activities "are limited by the amount of prescribed content, the typical forms of evaluation, the size of the groups, the demands of educational interaction with students, the duration of classes and the nature of the knowledge taught" (p. 174). Therefore, it is inferred that, when designing and executing it, the instructional model does not depend exclusively on the particular exercise or vision that the professor possesses.

It could be assumed, with regard to current instructional methods, that the strategy used to capture a research idea guides its development and the completion of the final degree project. It could also be related, on the other hand, to the lack of interest, motivation, and even understanding of such research, thereby generating the "All but Dissertation" (ABD); if so, what is the greatest difficulty that a student has when doing research work?

In the researchers' opinion, based on their experiences as tutors, directors, and thesis juries, one of the difficulties that students present when posing, explaining, and/or exposing a research topic can be located in a linear and predetermined way, which the universities and educational institutions require, when facing it; this is due to the follow-up of traditional patterns that may have worked in the past but that, in the 21st century, do not necessarily have a place.

Taking into account all the aforementioned aspects, it can be said that the main problem that this study covers and tries to answer can be subdivided into three parts: (i) the difficulty that students have in visualizing the standard content of a dissertation or degree project, despite the countless guides, books, and tutorials that exist in this regard, (ii) the difficulty that the tutors and directors of the research paper and/or dissertations have when tutoring, evaluating, or clearly visualizing the research proposed by the students, and (iii) the difficulty that the students have when summarizing their dissertation and/or degree project in front of the evaluation committee.

Considering that the listed problems may have one element in common, the following questions arise: what alternative can be offered to students to start, summarize, present, or explain a research project? What alternative-tool could be offered to the students different from current methodologies?

\section{Aims of the Research}

For this reason, the main aim of this paper is to propose and document a model to present research projects, either at the beginning (to visualize the idea), in the interim (to evaluate progress and monitor them), or at the end (to show/discuss its results), based on the proposal of the Canvas model by Osterwalder and Pigneur [7], but adjusted and modified to the academic field.

The Canvas Model for Research Projects or CMRP-here proposed-is not intended to contradict, criticize, or eliminate the existing methods envisaged for the development and construction of research work; it only 
seeks to offer a different, practical, and quick vision to visualize, summarize, and present a research project, especially in the educational field.

\section{Methodology}

A qualitative methodology has been used, with an emphasis on documentary research, which means that this study is based on data collected from sources that provided content related and/or linked to the purpose of this research.

To strengthen the scientific position of the study, inferential and deductive reasoning have been used.

According to Boddez et al. [8], inferential reasoning consists of the study of the premises that lead to obtaining conclusions after carrying out long and slow reasoning processes that can be represented as a modus tollens argument.

Ayalon and Even [9] explain that deductive reasoning is "the process of inferring conclusions from known information (premises) based on formal logic rules, where conclusions are necessarily derived from the given information, and there is no need to validate them by experiments" (p.235).

Based on the aforementioned concepts and aspects, the methodology chosen for this study follows the required steps to support the building of the model proposed here.

\section{Review of Literature}

4.1. Research Definitions. According to Williams [10], research is "at times mistaken for gathering information, documenting facts, and rummaging for information" (p.65), that is why it is necessary to offer definitions of the concept of research from an academic perspective. See Table 1.

Therefore, research seeks to offer answers, information, and/or knowledge different from those that are possessed or to corroborate the hypotheses associated with the phenomena present in different fields.

4.2. Project Definitions. Although several activities, depending on their nature, can be considered as projects, it is necessary to highlight the definitions linked to this activity to visualize with greater precision what is expected of it. See Table 2.

In other words, a project is an articulated, objective, and rational plan, with a defined period of time, which pursues the fulfilment of goals, usually focused on the creation of something new, which differs from what exists. That result can be a new product, a new service, or the acquisition of new knowledge.

4.3. Research Project Definitions. For Law [19], a research project is "a discrete scientific endeavour to answer a research question or a set of research questions" (p.1). They also explain that a research project "must include a description of a defined protocol, clearly articulated goal(s), defined methods and outputs, and a defined start and end date" (idem).
But, in a more academic perspective, according to [20], cited by Rahul [20], a research project is the activity of the "manipulation of things, concepts or symbols for the purpose of generalizing to extend, correct or verify knowledge, whether that knowledge aids in construction of theory or in the practice of an art" (p.1).

Therefore, in the academic field, a research project could also be understood as that temporary activity that seeks to promote investigation and analysis of a particular problem of a topic associated with the studies that are carried out to obtain a professional degree.

4.4. The Canvas for Business Models. As we have seen, a research project pursues accomplishing goals in a specific field and in a given time. In the administrative field, for example, a research project may be aimed at entering a market or discovering what customers want to receive. But, in the academic field, the research project seeks to answer an unknown or understand a phenomenon.

Taking into account the aforementioned aspects, before documenting and explaining in detail the Canvas Model for Research Projects (CMRP), proposed in this study, it is important to know and explain the instrument developed by Osterwalder and Pigneur in 2011 to elaborate business models. In their book, "Generating business models, a manual for visionaries, revolutionaries and challengers," Osterwalder and Pigneur [7] transformed the way of seeing, understanding, and making a business plan through what is now known as the Canvas model.

The model, made up of nine parts (see Figure 1) explains what a business proposal must have to capture the attention of customers, investors, and suppliers, making it easier to consolidate the idea that is owned, as well as the elements that make it up. And, in theory, they can make it possible.

The model proposed by Osterwalder and Pigneur [7] also offers a simple and practical way to go developing ideas about a particular business. This exercise allows both who owns the idea and who will be in charge of evaluating it to know the benefits, applications, characteristics, and projections of the proposed business. It is even possible to find tutorials on platforms such as YouTube, which ensures that Osterwalder and Pigneur's Canvas model for business allows a coherent idea to be raised in no more than five minutes if the administrative, market, suppliers, and clients' aspects have been previously analysed.

Osterwalder and Pigneur [7] explain how, in each box, the vital aspects of a business plan can be summarized, dedicating more space, from the visual point of view to those elements that require attention, and even recommend printing the business model Canvas "in large format, so that participants can annotate and comment in group on the elements of the model with self-adhesive notes or markers. It is a practical tool that encourages understanding, debate, creativity and analysis" (p. 42).

The above consideration suggests a general visualization process that allows us to appreciate, as a whole, the complete business idea and to project, reduce, improve, or suppress, 
TABLE 1: Research definitions.

Tiwari [11]

Babbie (1998), quoted by more [12]

Western Sydney University [13]

Williams [10]

DiscoverPhDs [14]
Research is defined as a "careful consideration of study regarding a particular concern or problem using scientific methods" (p.2)

Research is "a systematic inquiry to describe, explain, predict and control the observed phenomenon. Research involves inductive and deductive methods" (p.1).

Research is defined as "the creation of new knowledge and/or the use of existing knowledge in a new and creative way so as to generate new concepts, methodologies and understandings." (p.1). And this could include "synthesis and analysis of previous research to the extent that it leads to new and creative outcomes" (idem).

Research is "the process of collecting, analysing, and interpreting data in order to understand a phenomenon" (p.65) Research is "the process of discovering new knowledge" (p.1)

TABLe 2: Project definitions.

Yarbrough [15]

Management Study Guide [16]

Stakeholdermap.com [17]

University of Illinois [18]
A project is "a set of tasks which must be completed in order to arrive at a particular goal or outcome." (p.1). Additionally, "depending on the size and scope of the project, these tasks may be simple or elaborate, but all projects can be broken down into objectives and what needs to be done to achieve them" (idem).

A project is "an activity to meet the creation of a unique product or service and thus activities that are undertaken to accomplish routine activities cannot be considered projects" (p.1).

A project is "a temporary venture to produce a new and unique deliverable. A deliverable could be a tangible product, a service or achievement of a required outcome" (p.1).

A project is defined as "an effort to create or modify a specific product or service. Projects are temporary work efforts with a clear beginning and end" (p.1).

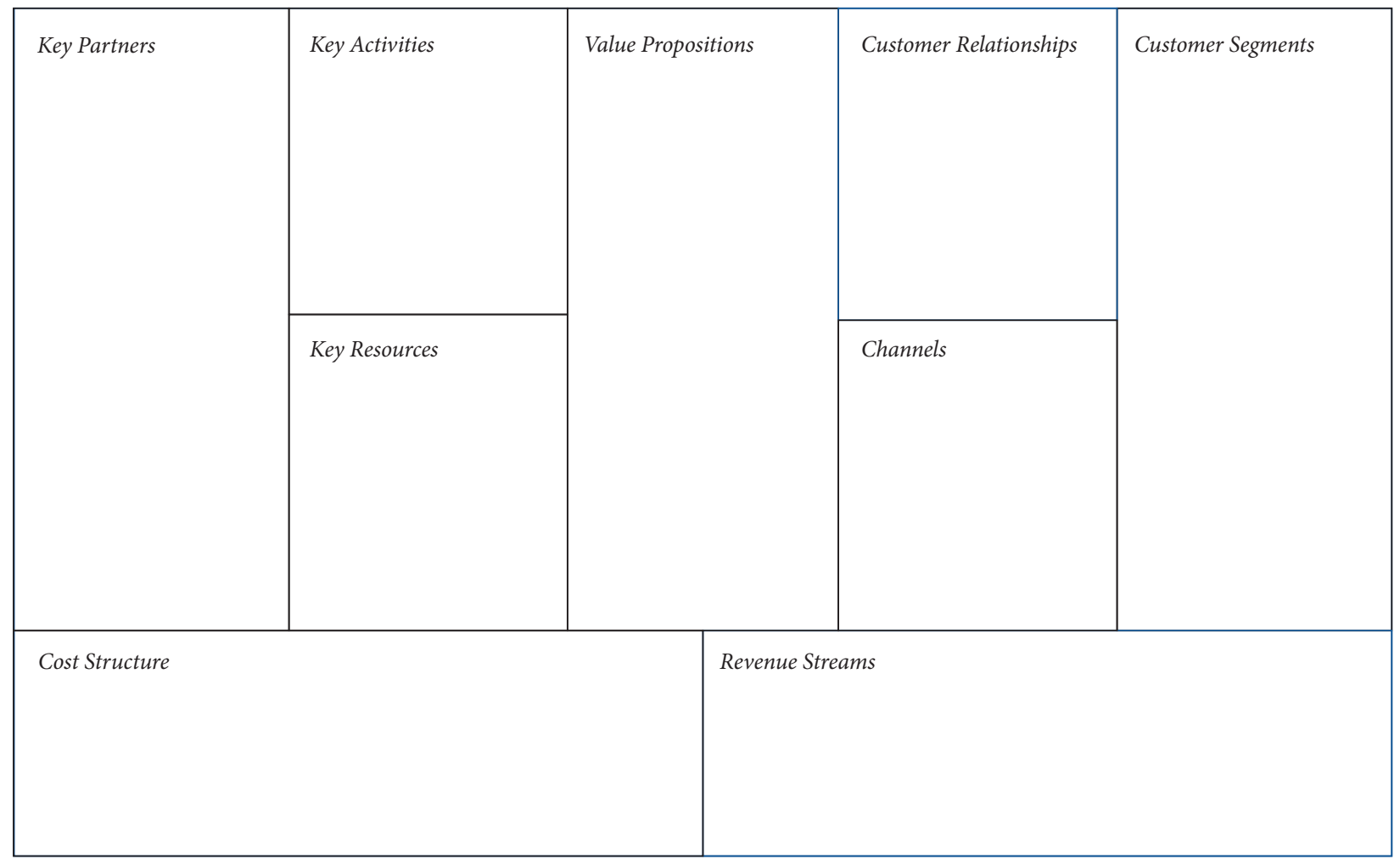

Figure 1: Template for the business Canvas model. Elaborated by the researcher based on Osterwalder and Pigneur [7], p. 44.

just by pointing out four actions, anything that can serve, or prevent, the optimal development of the idea of business.

In the Osterwalder and Pigneur [7], book introduction, the following can be read:

Innovation in business models is not really something new. The founders of Diners Club applied it when they introduced the credit card in 1950, as did Xerox, which introduced the copier rental and pay-per-copy system in 1959. In fact, innovation in business models dates back to the century XV, when Johannes Gutenberg was looking for applications for the mechanical printing device he had invented. [7], p. 8). 
But innovating, as is known, is not limited solely and exclusively to business models, innovation is part of almost everything that takes place in life, especially in the field of science, and today, more than ever, it is expected to see in education.

In fact, Osterwalder and Pigneur [7] affirm that the Canvas "is not for exclusive use by for-profit organizations, it is also useful for non-profit organizations, charities, public sector entities and for-profit social enterprises" (p. 264). In this regard, Rivas [21] assures that "today innovation is experienced as external pressure. It seems an imperative that marks the educational defeat in a time when everything changes except the classrooms" (p. 114).

That is why Rivas [21] begins his dissertations talking about educational innovation, which he defines as "a vital force, present in schools, educators, projects and policies, that is capable of recognizing the limitations of the traditional educational matrix and alter it for the benefit of our students' 21st century learning rights" (p. 21).

However, situations such as the one experienced with the arrival of COVID-19, in the first quarter of 2020, which have required rethinking the educational model, could be generating changes in the way some instructional methods are perceived. This situation could become an excellent input for critical and constructive ways in which research projects or final degree projects are taught, developed, and presented. Canvas model can generate innovation in terms of accommodating proposals such as the one that will be presented in the following, which seeks to alter the present patterns in the education fields, as exposed by Rivas [21].

\section{The Canvas Model for Research Projects Proposal}

If something as broad and complex, such as proposing a business proposal, can be efficiently summarized in nine boxes, as stated in the Canvas model proposed by Osterwalder and Pigneur [7], could this not also be applied to an investigation?

Technically speaking, the Canvas model could be applied to various fields of action; it should not necessarily be limited to business proposals. For example, Osterwalder and Pigneur [7] state that to develop a business plan:

Adopting the customer perspective is a guiding principle of the business model design process. The customer perspective should be a source of information for making decisions about value propositions, distribution channels, customer relationships and sources of income. [7], p. 128).

The same logic applies, in the academic field, to juries and thesis tutors, since if the perspective of the evaluator or mentor is adopted, it would be easier to adjust the proposal of the project that you want to do or for the dissertation of any project.

In this order of ideas, in a Canvas model for a research project (CMRP), the elements generally accepted for this purpose must be respected, as listed by Hernández, Fernández, and Baptista [22], as summarized in Figures 2 and 3.
As can be seen, Hernández, Fernández, and Baptista [22] conceive the qualitative research process in 10 steps, from the moment the research idea is generated until the results obtained are reported, while the qualitative research process limits it to only 9 steps, as shown in Figure 3.

Although it is true that some authors propose the inclusion of the "state of the art," as a previous step to the theoretical framework, the variations regarding the structure of a research project are very few, and the existence of the following points could be assumed as components from a standard investigation:

(1) Title of the research

(2) Problem statement

(3) Research question and hypothesis (if any)

(4) General purpose

(5) Specific objective

(6) Rationale of the study

(7) Scope and/or limitations

(8) Theoretical framework

(9) Methodological framework

(10) Expected results or conclusions

Based on the above elements, a Canvas of 10 boxes can be generated to summarize, in a practical way, both visual and documentary, what the project to present or defend would be. See Figure 4.

As can be seen in Figure 4, each box has a specific position on the Canvas. This situation responds to the way in which the project should be carried out by the student and reviewed by the tutor or evaluator.

Each position of the boxes has been designed according to its correlation with the others to maintain coherence in the discussion, presentation, and evaluation of its contents. See Figure 5.

Figure 5 shows what should be the flow of information that the student must follow at the time of expressing his idea or research proposal and how the tutor, director, or advisor of the degree project and/or dissertation should review, correct, and guide the student in the development of it.

In point number 1 of Figure 5, it can be seen how the title of the research is closely related to the description of the problem associated with it. This is considered the first step to take since it is easier for the student to think of a problem and arrive at the title or to think of a title and then describe the problem associated with it.

Once the title and the problem have been established, the student must explain the general purpose of the research-the main aim-which is why the arrow at point No. 2 in Figure 5, shows how the specific objectives should be associated with the general purpose. In the same way, the main aim has to be closely related to the "rationale of the study" development.

The aforementioned aspects also allow the tutor to observe the logic of the investigation and facilitate guidance -if required - in the approach to the points that this section includes. 


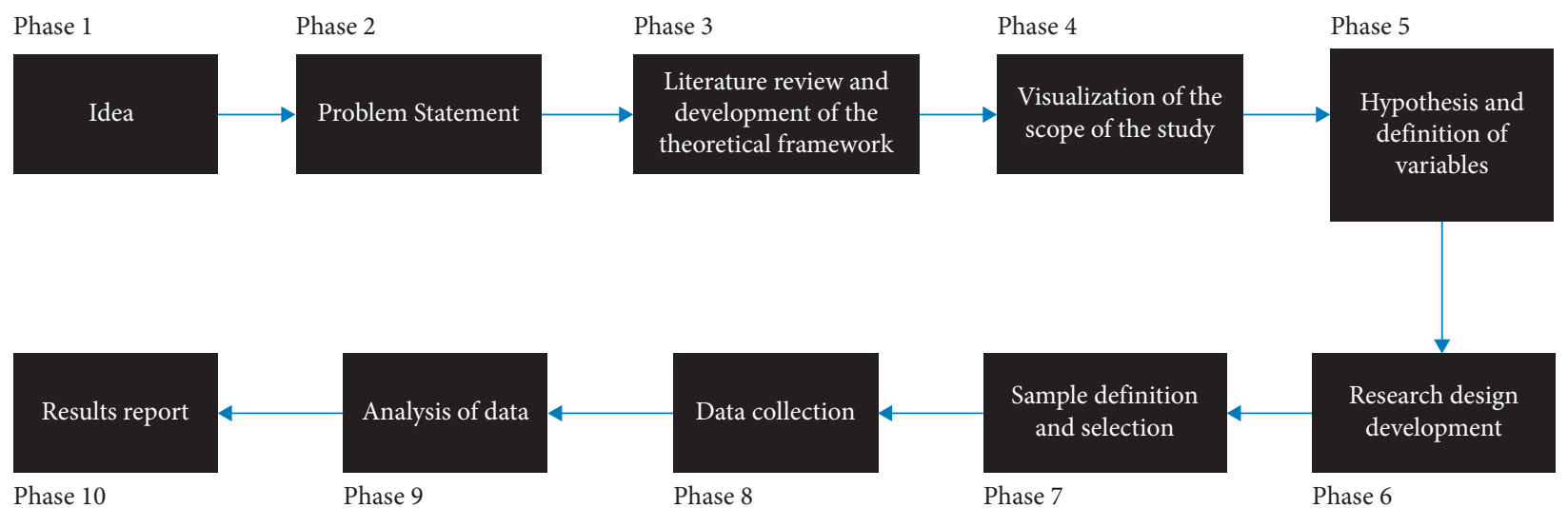

Figure 2: Quantitative research process. Source: Hernández, Fernández, and Baptista [22], p. 38.

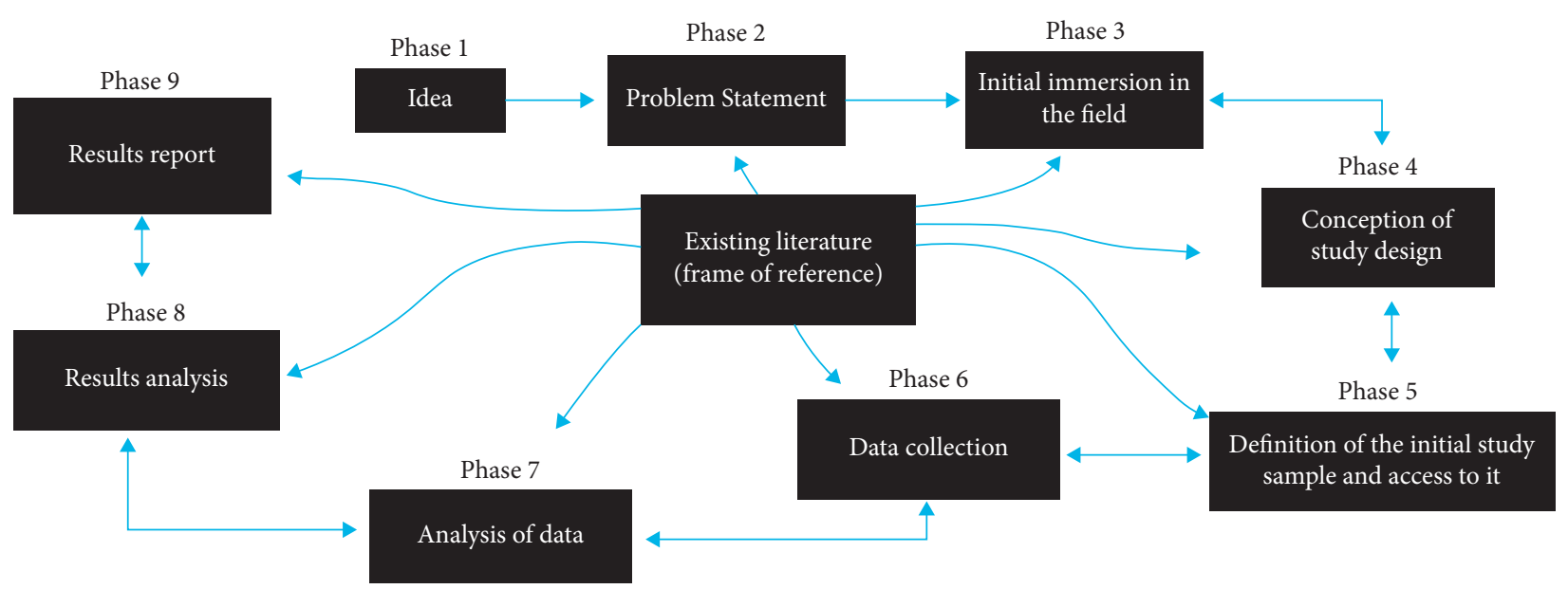

Figure 3: Qualitative research process. Source: Hernández, Fernández, and Baptista [22], p. 40.

\begin{tabular}{|c|c|c|c|c|}
\hline \multirow[t]{2}{*}{$\begin{array}{l}\text { 6. RATIONALE OF THE } \\
\text { STUDY }\end{array}$} & 4. GENERAL PORPUSE & 1. TITLE OF THE RESEARCH & $\begin{array}{l}\text { 7. SCOPE AND/OR } \\
\text { LIMITATIONS }\end{array}$ & $\begin{array}{l}\text { 8. THEORETICAL } \\
\text { FRAMEWORK }\end{array}$ \\
\hline & 5. SPECIFIC OBTETIVES & 2. PROBLEM STATEMENT & $\begin{array}{l}\text { 3. RESEARCH QUESTION } \\
\text { AND HYPOTHESIS (if any) }\end{array}$ & \\
\hline \multicolumn{3}{|c|}{ 9. METHODOLOGICAL FRAMEWORK } & \multicolumn{2}{|c|}{ 10. EXPECTED RESULTS OR CONCLUSIONS } \\
\hline
\end{tabular}

FIgUre 4: Canvas Model for Research Projects (CMRP). Elaborated by Félix Socorro. November 2019. 


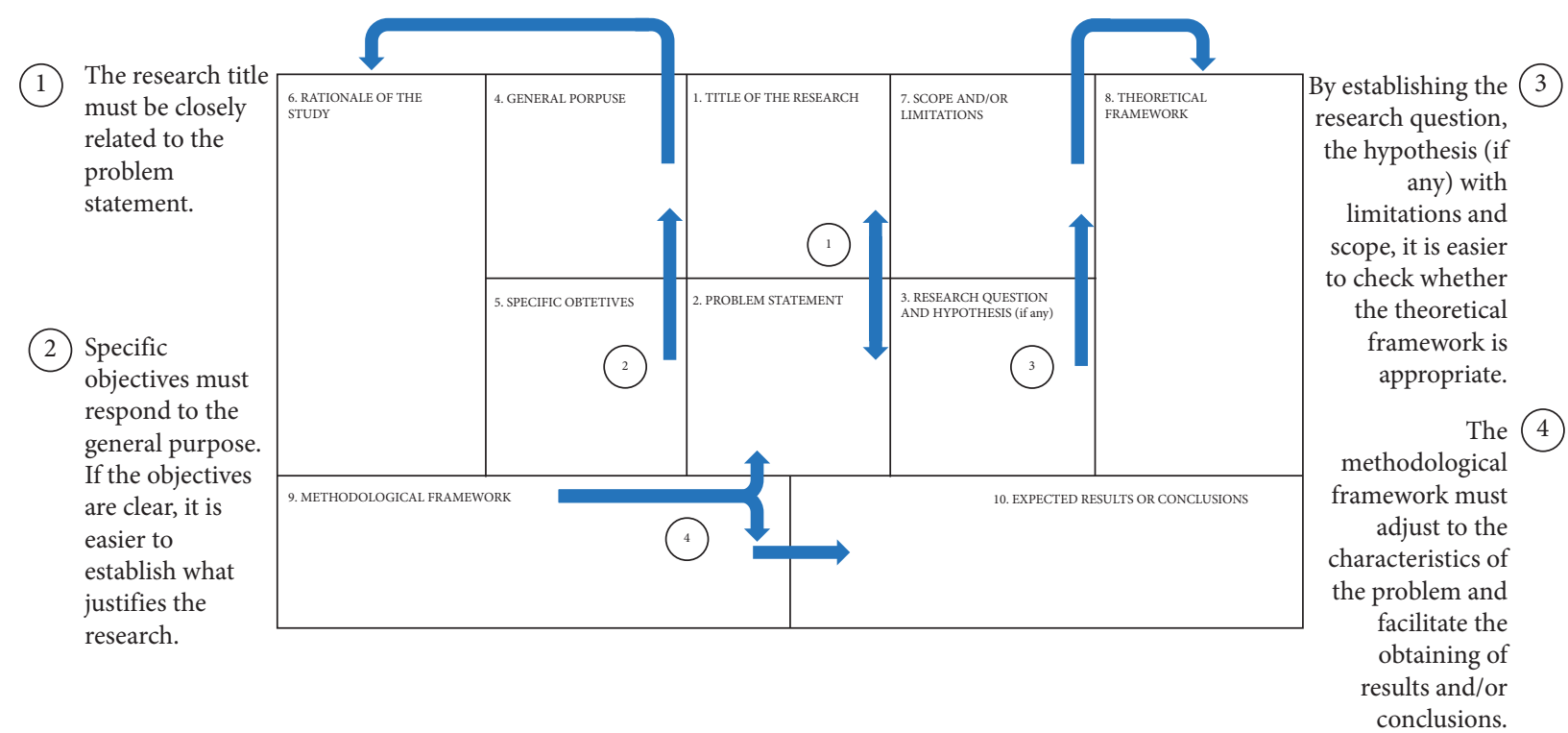

Figure 5: Relationship among the boxes of the Canvas Model for Research Projects (CMRP). Elaborated by Félix Socorro. November 2019.

The follow-up of the research logic can also be seen in point 3 of Figure 5.

Once the students have determined the title of their research, they know the problem they want to address, and they have explained the general purpose of their study, the objectives, and the rationale, it will be easier for them to write the question they hope to answer and visualize the scope and/or the limitations of their research; therefore, putting together the theoretical framework that will support their study will be easier for them.

In this particular step, the tutor could more easily guide the relationship that should exist between the research question and/or the hypotheses that may arise since the student has developed a good part of the content that is required for this.

Part 4 of Figure 5 has a special feature. This part is directly linked to the problem that arises, so the methodological framework that is approached must consider the elements described in the statement of the problem, in such a way that it can be chosen between a qualitative, quantitative, or mixed methodology depending on the case.

In this section, both the student and the tutor will be able to discuss the vision of the ideal methodology to scientifically address the problem.

The arrow at point 4 also points to box no. 10 of the proposed Canvas; this refers to the double function that this instrument has.

The first function is aimed at facilitating the assembly of the investigation and at summarizing the results that are expected to be achieved once it has been carried out.

The second function aims to show a summary of the research carried out, so that box 10 would offer the conclusions that the researcher has reached.

In both cases, the tutor and/or the evaluation committee will be able to see the entire research process reflected in the preliminary stage as part of the draft and development of the same and in the final stage as a presentation of the results and the steps that they were given to reach them.

\section{Explanation of the Canvas Model for Research Projects (CMRP)}

Unlike the model proposed by Osterwalder and Pigneur [7], for business, the Canvas Model for Research Projects or CMRP consists of 10 boxes and not 9 , designed in such a way that their proportion facilitates the understanding of the extension required for each line, as explained in the following.

6.1. Box 1: Title of Research. This box is small, suggesting the limited use of words that should be used for the title of an investigation.

Hernández et al. [22] suggest that the title should be "brief but informative and that "sensationalist" terms be avoided" (p. 374) and "it should not be too short or too long (...) [and that] varies between 12 and 20 terms (60 to 80 characters)" (idem), understanding that by "terms" the three authors refer to "words."

Meléndrez [23] recommends that the title should be "concise and specific, it will adequately reflect the objective of the thesis and the fundamental aspects in which the applicant emphasizes his work" (p. 19), which justifies the size of the box.

6.2. Box 2: Problem Statement. This box is also small, which suggests accurately describing the problem to be addressed and requires focusing on the problem and having the ability to synthesize to describe it.

At this point, Meléndrez [23] states that "a problem well posed is a problem already partially solved" (p.22), so it should be understood that the more concrete the problem statement is, the easier it will be to understand the objectives, the rationale of the study, and the results obtained. 
6.3. Box 3: Research Question and Hypothesis (If Any). This box is the same size as the previous ones and should only show the research question, worded in a concrete way, and the main hypothesis of the work, if any, also worded precisely.

6.4. Box 4: General Purpose. The general purpose is usually direct, concrete, and clear enough to be considered the fundamental goal of the investigation.

6.5. Box 5: Specific Objectives. It is suggested that, as far as possible, the specific objectives are not greater than 3 . Authors such as Kaplan and Norton [24] suggest, even in the case of the formulation of business strategies, to have a manageable number of objectives, which should not be ruled out in the case of research projects.

6.6. Box 6: Rationale of the Study. Bernal [25] explains that "all research is aimed at solving a problem; therefore, it is necessary to justify, or state, the reasons that deserve the investigation. Likewise, its coverage or dimension must be determined to know its viability" (p. 106) and considers that it must be considered from 3 angles: theoretical, practical, and methodological, highlighting the contribution it will have in each of these areas. That is why this box is broader than the previous ones.

6.7. Box 7: Scope and/or Limitations of the Research. In this box, the limits of the research should be briefly explained, which covers or hopes to cover, in periods of years, population, market, niche, region, or to where it extends or concentrates.

For Bernal [25], the researcher "must make the limitations of the project explicit in order to facilitate its viability" (p. 107) and considers that there must also be 3 aspects: time, space or territory, and resources.

Regarding the scope of the research, Hernández, Fernández, and Baptista [22] explain that this refers to whether the study will be "exploratory, descriptive, correlational or explanatory. That is, how far, in terms of knowledge, is it possible for the study to go?” (p. 99).

6.8. Box 8: Theoretical Framework. This box is wide so that at least one significant antecedent and at least three authors, sources, or currents that support the topic can be indicated.

For Gómez [26], the theoretical framework is "an instrument of great importance, since it allows us to specify, organize, and clarify all the elements that constitute the description of the problem" (p.43); therefore, what should be listed in this box gives value to what you want to investigate or justifies the problem you want to tackle.

6.9. Box 9: Methodological Framework. This box should summarize the characteristics of the methodology used (qualitative, quantitative, or both) and why, whether numerical data will be available or not, how they will be analysed, if any, and how these results will be shown.
It is important to note that, for Cortés and Iglesias [27], this section should be made up "of a whole series of logically structured and interrelated steps” (p. 8).

6.10. Box 10: Expected Results and/or Conclusions. In this box, the results of the research finding that respond to the objectives and the research question and hypotheses or the conclusions that respond to the same criteria previously indicated must be presented.

\section{Practical Example of the Canvas Model for Research Projects (CMRP)}

In order to illustrate in a practical way the application of the Canvas Model for Research Projects (CMRP), a research project proposal will be shown in the following, adjusted to the suggested scheme. See Figure 6.

In this example, it can be seen how each box has a correlation with those that accompany it, which aims to facilitate the logical development of the project and, at the same time, its evaluation, correction, and revision, whether by colleagues, tutors, or professors.

Note that, in the example, the phrase "expected results" has been highlighted in box number 10; this is because it is an investigation in progress and not a finished work.

\section{Main Contributions of the Canvas Model for Research Projects (CMRP)}

In addition to the summary presentation of a research project, whether to be developed, under development or completed, the CMRP offers the following:

(a) Clarity in the investigative aspect: it makes it easier to find a correlation between its components and to identify weaknesses, contradictions, or redundancies to point out only three aspects

(b) It facilitates the explanation of the investigation

(c) It highlights the most relevant aspects of the investigation

(d) It reduces exposure time

(e) It facilitates the correction, addition, or replacement of content

(f) It focuses attention on what academically is expected to dominate whoever does it

(g) It can be used for both qualitative and quantitative research and even for those that combine both types of research

\section{The Canvas Model for Research Projects (CMRP) and a Trial Empirical Validation}

As in business, every idea must be tested before it is offered to the market. Therefore, testing the CMRP before presenting it as an alternative in the orientation, monitoring, and evaluation of academic research projects was considered necessary. 


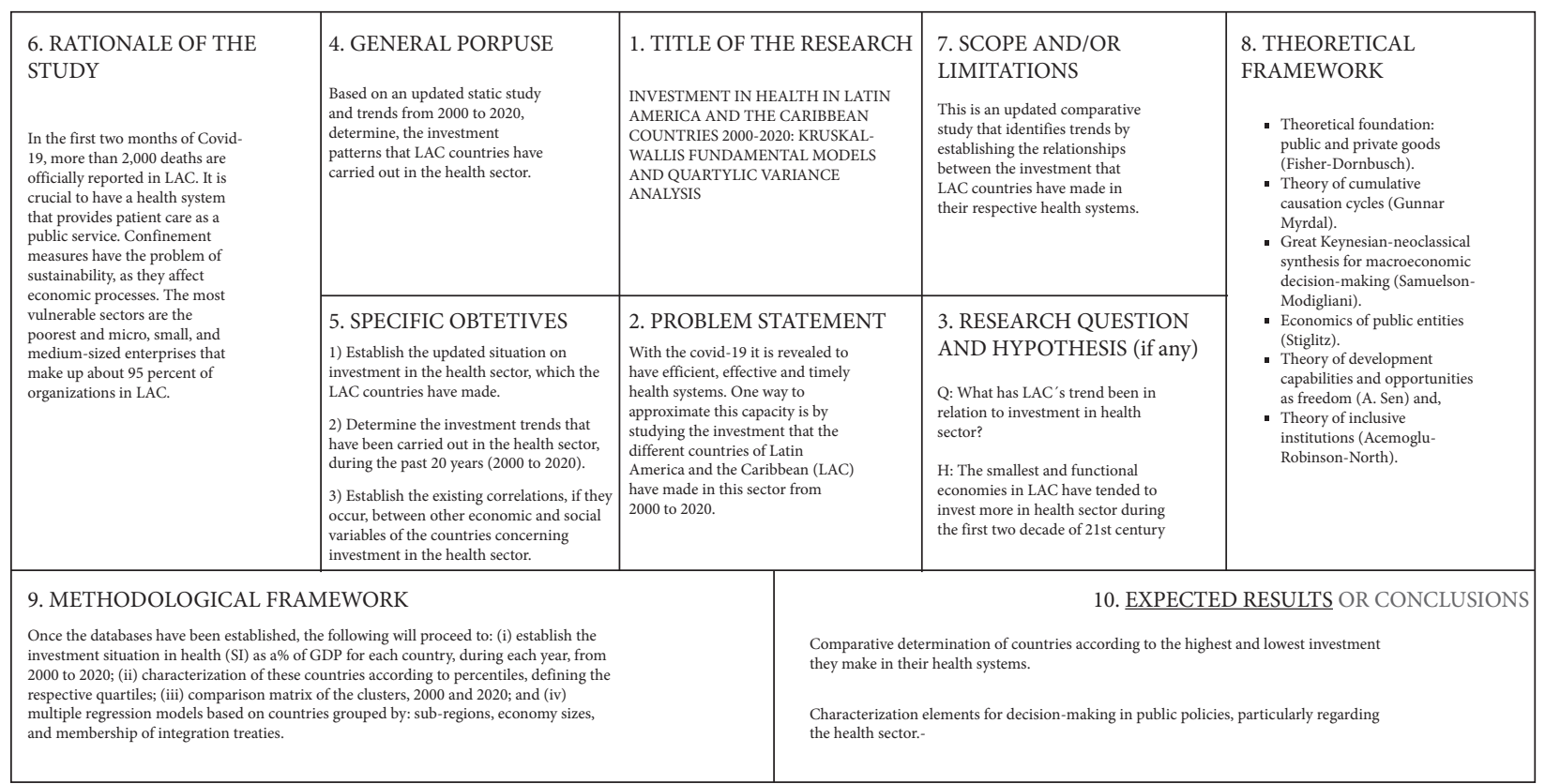

Figure 6: Practical example of the Canvas Model for Research Projects (CMRP). Elaborated by Socorro and Reyes. November 2019.

Although one of the expectations of the study is to document the CMRP before carrying out a significant empirical validation, which includes all the elements presented here, a small test was not ruled out that allowed observing how some students would respond to the model.

Therefore, a simple and preliminary experiment was devised that would allow knowing its effectiveness without disclosing-in an evident way-its characteristics or methodology.

During the second academic semester of 2019, the Canvas Model for Research Projects (CMRP) was used, in a trial period, in 10 research papers (assigned to be tutored), in undergraduate students of business administration, throughout the tutorial of the study they were carrying out. These students had completed all their studies but were late in submitting their final research paper for two consecutive periods.

As each research paper was made up of 2 students, during the trial period, 20 students were asked to build the research paper in the order in which the proposed model suggested it. This group of students was named Team A.

While 18 students, responsible for 9 research papers, were guided according to the traditional methodology. These 18 students were tutored by a different professor who was unaware of the characteristics of the Canvas Model for Research Projects (CMRP) proposed in this study. But the professor was aware of the trial. This group of students was named Team B.

The result was as follows:

(i) Team A: nine of ten research papers were finished on time. The first 3 of the 10 research papers obtained an $\mathrm{A}+$ grade, 2 of them obtained an A, 4 of them obtained a $\mathrm{B}+$ grade, and 1 of them was not presented for evaluation. (ii) Team B: while 6 of the 9 studies carried out without using the CMRP methodology were evaluated, 3 research papers were not presented for evaluation. Two of the research papers obtained a $\mathrm{B}+$ grade, 2 obtained a B grade, 1 obtained a $\mathrm{C}+$ grade, and 1 of them was rejected

According to school statistics, the average grade point for students has been B- grade for the past five years.

Through an unstructured interview, where 15 of the 20 students who participated in the trial expressed their opinion about the CMRP, it was obtained as a result that they felt better oriented in the researching process. These 15 students affirmed that they could visualize more clearly what was expected both of them as researchers and the research project.

The trial was done to give shape and consistency to the proposed model; although the results are not considered conclusive, they served as the basis for developing the proposed model.

It is important to point out that the idea of the CMRP is none other than to facilitate the carrying out of research work at the academic levels where it is required to complete the studies and, with this, significantly reduce the "All but Dissertation" (ABD) syndrome.

Hence, it is expected that, once the article is published, it will be used it content as a conceptual basis to carry out an empirical contrast with a larger sample and relate the results in a larger period of time to the "All but Dissertation" (ABD) syndrome.

\section{Conclusions}

Even though the Canvas methodology proposed by Osterwalder and Pigneur [7] was designed for business formulation and to facilitate their understanding and visualization 
of business and entrepreneurship, the idea seems to have a place in other areas such as academic investigation.

As Rivas [21] exposes in his book, the educational process requires changes and innovation, so introducing methodologies that have been successful in other fields and introducing them in the academic environment could represent innovations that would be adjusted to contemporary dynamics.

The way in which a research project is presented is not oblivious to changes and should not always be observed from a linear and traditional perspective that has been used in recent decades since it is logical to think that it will not always adjust to the requirements and expectations of present and future generations, or that will live up to the demands of the scenarios that may arise due to social, cultural, economic, or any other kind of changes.

It is important to remember that Barker [28] explained that assuming that there is only one way of doing things leads to paradigmatic paralysis, which prevents seeing, understanding, and accepting creative solutions or proposals that challenge the generally accepted paradigm.

In this sense, the Canvas Model for Research Project$s$ - or CMRP - not only offers an alternative to presentation, discussion, and defence of research projects in the academic field but also poses a different paradigm that facilitates the teaching of the research process and the maturation of a research idea in any field, which answers the question asked by the proposing researchers.

The Canvas Model for Research Projects, or CMRP, could be a tool to help students visualize, write, and complete their research papers successfully. If so, this could help reduce the "All but Dissertation" (ABD) syndrome mentioned in the introduction, since the model seeks to contribute to structuring any academic or nonacademic research in a clear and precise way.

Based on its composition, it is possible to observe that the CMRP chases to reach what is expected-for both the institution and the tutor-of the student as a researcher. Additionally, it is possible to infer that the proposed model is aimed at strengthening and improving the tutorstudent relationship, as well as what is expected to be achieved in the student-tutor and/or researcher-institution relationship.

Finally, the Canvas Model for Research Projects could serve as a tool for the discussion, analysis, correction, and evaluation of any academic research projects, even the configuration of the proposed model could facilitate the presentation and diffusion of them.

\section{Data Availability}

Data sharing is not applicable to this article as no new data were created or analysed in this study.

\section{Conflicts of Interest}

The authors declare no conflicts of interest.

\section{References}

[1] J. López, http://camp.ucss.edu.pe.http://camp.ucss.edu.pe/ ingenium/index.php/sistemas/124-que-es-una-tesis-y-paraque-sirve, 2019.

[2] UAO, https://www.uao.edu.co/informacion/trabajo-degrado-pregrado-general, 2021.

[3] J. L. Abreu, "Síndrome todo menos tesis (TMT)," Daena: International Journal of Good Conscience, vol. 10, no. 2, pp. 246-259, 2015.

[4] Y. Ferrer and M. Malaver, "Factores que inciden en el síndrome de Todos menos Tesis (TMT) en las maestrías de la Universidad del Zulia," Opción, vol. 16, no. 31, pp. 112-129, 2000.

[5] S. Gheller, "Estrategia de intervención para resolver el síndrome "Todo Menos Tesis" en el Componente Docente de la Escuela de Educación de la Universidad Central de Venezuela," Anales, vol. 2, pp. 13-32, 2002.

[6] A. Badia and F. Gómez, "Condiciones del contexto instruccional que afectan el diseño de la enseñanza del profesor," Educación XX1, vol. 17, no. 2, pp. 169-172, 2014.

[7] A. Osterwalder and Y. Pigneur, Generación de Modelos de Negocios, DEUSTO, Barcelona, Spain, 2011.

[8] Y. Boddez, J. D. Houwer, and T. Beckers, "The inferential reasoning theory of causal learning: toward a multi-process propositional account," in The Oxford Handbook of Causal Reasoning, M. R. Waldmann, Ed., Oxford University Press, Oxford, England, pp. 1-37, 2017.

[9] M. Ayalon and R. Even, "Deductive reasoning: in the eye of the beholder," Educational Studies in Mathematics, vol. 69, no. 3, pp. 235-247, 2008.

[10] C. Williams, "Research methods," Journal of Business \& Economics Research, vol. 5, no. 3, pp. 65-72, 2007.

[11] A. K. Tiwari, "Research methodology," 2020, https://lkouniv.ac. in/site/writereaddata/siteContent/202004161028054465pravish_ its_Research_Methodology_2.pdf.

[12] H. More, https://thefactfactor.com/research_methodology/ research/1144/, 2019.

[13] University Western Sydney, "Definition of research," 2020, https://www.westernsydney.edu.au/research/researchers/ preparing_a_grant_application/dest_definition_of_research.

[14] DiscoverPhDs, "What is research? - purpose of research," 2020, https://www.discoverphds.com/blog/what-is-researchpurpose-of-research.

[15] Q. Yarbrough, "Project definition: the meaning of a project," 2021, https://www.projectmanager.com/blog/project-definition.

[16] Management Study Guide, "What is a project ?," 2021, https:// www.managementstudyguide.com/what-is-project.htm.

[17] Stakeholdermap.com, "What is a project?," 2021, https:// www.stakeholdermap.com/project-management/what-is-aproject.html.

[18] University of Illinois, "Project definition recommendations," 2021, https://www.aits.uillinois.edu/services/professional_ services/pmo/project_management_toolkit/project_ definition_recommendations/.

[19] I. Law, "Research project definition," 2021, https://www. lawinsider.com/dictionary/research-project.

[20] C. Rahul, “A review on: research methodology - I," 2013, https://www.pharmatutor.org/articles/review-on-researchmethodology.

[21] A. Rivas, Cambio e innovación educativa: las cuestiones cruciales, Santillana, Buenos Aires, Argentina, 2017. 
[22] R. Hernández, C. Fernández, and P. Baptista, Metodología de la Investigación, McGraw-Hill, Mexico, 2013.

[23] E. H. Meléndrez, Cómo Escribir Una Tesis, Universidad Católica de Valparaiso, Valparaiso, Chile, 2006.

[24] R. S. Kaplan and D. P. Norton, Mapas Estratégicos, Paidos, Bogota, Colombia, 2016.

[25] C. A. Bernal, Metodología de la Investigación, Pearson, Bogota, Colombia, 2010.

[26] S. Gómez, Metodología de la Investigación, Red Tercer Milenio, México, 2012.

[27] M. E. Cortés and M. Iglesias, Generalidades sobre Metodología de la Investigación, Universidad Autónoma del Carmen, Ciudad del Carmen, Mexico, 2004.

[28] J. A. Barker, Paradigms: The Business of Discovering the Future, Harper Collins Publishers Inc, New York, NY, USA, 1993. 